\title{
EVALUATION OF DIFFERENTIAL MONOCYTES IN THE DMBA/HCPE CARCINOGENESIS MODEL UNDER THE INFLUENCE OF SOME PHYTOCHEMICAL AGENTS
}

\author{
Magda M. Aly Hassan * and Ghada A. Abd El Atif **
}

\begin{abstract}
Dimethylbenza-a-anthracene (DMBA), is a potent carcinogen that has an immunosuppressive effect on hamsters. Nigella sativa whole oil (NSO) and thymoquinone (TQ), are phytochemicals that have an antioxidant and protective action on the hamster cheek pouch epithelium (HCPE/ DMBA) carcinogenesis model.
\end{abstract}

The aim is to find which of the two ingredients TQ \& NSO has more immune-enhancing activity comparable with its protective and/or chemotherapeutic activity against the carcinogenic effect of DMBA on HCPE, through evaluation of different peripheral monocytes.

Material \&methods: NS whole oil (NSO), and thymoquinone (TQ) were given before-, withor after DMBA painting the hamster's left cheek pouch. Before each animal's sacrificing, two ml of blood was drawn in a fine heparinized capillary tube to estimate the total WBCs, total lymphocytes, MID cells, and granulocyte's count by an automatic count system (Cell-DYN1700).

Blood results were statistically analyzed using One-way ANOVA test between groups for each phase followed by LSD (Least Square Difference) test for multiple comparisons between different phases. All pouches were surgically-excised and examined microscopically to compare the histopathologic changes of DMBA-painted pouches, NSO-and TQ-treated groups, with untreated pouches as well as pouches of the untreated group.

Histopathologic results: the groups given each of the tested ingredients for 2 wks showed normal appearing thin epithelium, with slight hyper-keratinization as compared with untreated pouches. Severe epithelial dysplasia was seen after 6 wks of DMBA, but when NSO or TQ was given for $2 \mathrm{wks}$ followed by DMBA for $6 \mathrm{wks}$, mild dysplasia was seen i.e. both have protective effect. When DMBA for $6 \mathrm{wks}$ was followed by NSO or TQ for $6 \mathrm{wks}$ mild dysplasia was recorded .i.e. both had a therapeutic effect through regressing severe dysplasia to mild dysplasia in 6 weeks.

Mononuclear cells results: DMBA for $6 \mathrm{wks}$ resulted in statistically significant reduction in total WBCs \&lymphocyte counts than control group, as well as when DMBA for 6wks was followed

* Professor Department of Oral Pathology, Faculty of Dentistry, Suez Canal University, Egypt

** Lecturer Department of Oral Pathology, Faculty of Dentistry, Suez Canal University, Egypt 
by either ingredient for 6 wks compared to controls. When NSO, or TQ were given for 2 wks resulted in statistical significant elevation in lymphocytes count. Statistically significant elevation in total WBCs\& lymphocytes' count was found when DMBA was given for 6wks, followed by TQ for 6 wks compared to the group given DMBA followed by NSO or to the control group. Only TQ for 2 wks followed by DMBA, resulted in statistically significant reduction in granulocytes. No significant differences were found in MID or granulocytes between all groups.

In conclusion both NSO \&TQ showed potential protective / therapeutic effect against DMBA carcinogenic activity with different levels of protection.

KEY WORDS: Nigella sativa whole oil (NSO), thymoquinone (TQ), peripheral blood cells, hamster cheek pouch epithelium, HCPE/DMBA carcinogenesis model.

\section{INTRODUCTION}

The sixth most leading cause of malignancyrelated death worldwide is oral squamous cell carcinoma (OSCC). It accounts for about 90\% among the head and neck cancers ${ }^{1}$. A close relationship between oral cancer patients, smokers and alcohol drinking people is very clear ${ }^{2}$.

Since the first work to induce oral squamous cell carcinoma (SCC) in the hamster cheek pouch (HCP) using dimethyl benza-a-anthracene $(\mathrm{DMBA})^{\mathbf{3}}$, this model has been extensively used to study the biologic pathway, prevention or treatment of SCC as it mimics much those events in human oral $\mathbf{S C C}^{(4,5 \& 6)}$.

The important biologic markers in both human OSCC and hamster buccal pouch (HBP) carcinoma had been studied, and the key signaling pathways in both models were comparable. Oxidative DNA damage, markers of cell survival and proliferation were similar as well as down regulation of apoptosis markers, over expression of invasiveness and angiogenesis markers were comparable. The HBP model is an important tool for monitoring human oral oncogenesis ${ }^{6}$.

Anticancer drugs developed from natural compounds or isolated from medicinal plants as active constituents were found to have various biological activities ${ }^{7}$.

The presence of rich biological active compounds in Nigella sativa volatile oil (NSO) has highlighted its traditional medicinal use ${ }^{8}$. Many active principles have been isolated from Nigella sativa seeds (NS) ${ }^{9}$, including thymoquinone (TQ) which is the bioactive and a principle constituent of NS. It was shown to have an anti-allergic, anti-oxidant, anti-diabetic as well as anti-tumor compound ${ }^{\mathbf{1 0}}$.

In last decades, many researches have been done to understand the mechanism of pharmacological actions of the plant-derived natural substances, as NS extract. It increases the activity of antioxidant enzymes (catalase, glutathione peroxidase, and glutathione-s-transferase) and acts as a free radical scavenger. They are used as an anti-cancer agent via modulation of the activities of many molecules such as p53, p73, activation of caspases, and generation of ROS. It also suppresses inflammatory mediators, leukotrienes, prostaglandins, and B cell-mediated immune response while balances Th1/ Th2 responses and potentiates $\mathrm{T}$ cell and natural killer cell-mediated immune responses ${ }^{11}$.

It was found that NS essential oil and its four constituents (thymoquinone, carvacrol, t-anethol, and 4-terpineol) have anti-oxidant effect in different chemical assays like diphenyl- picrylhydracyl assay for non-specific hydrogen atom or electron donating activity. Also, OH-radical scavenging property in the assay for non-enzymatic lipid peroxidation in liposomes and the deoxyribose degradation assay ${ }^{\mathbf{1 2}}$.

It had been hypothesized that these NS ingredients have an antioxidant and cytotoxic 
activities as their main action to prevent, delay or co-treat malignancies including human cancer cell lines as colorectal, ovarian and breast cancer cells $^{(10,13,14)}$.

It was demonstrated that the anti-inflammatory activities of both systemic and local administrations of essential oil from Nigella sativa ${ }^{\mathbf{1 5}}$, and it has been shown that thymoquinone (TQ) inhibits the production of 5-lipoxygenase through an antioxidative mechanism ${ }^{\mathbf{1 6}}$.

In a rat model, the volatile oil of NS seeds tested for its immunomodulating and cytotoxic properties. Antibody titer for experimental animals was significantly decreased, as well as splenocytes and neutrophils counts, however a rise in peripheral lymphocytes and monocytes in the experimental group. It also found to be cytotoxic to both fibroblast cells and five human cancer cell line ${ }^{17}$.

TheTQactions were postulatedand documented in different healthy and diseased conditions. The effect of oral TQ and its metabolite dihydrothymoquinone (DHTQ) on hepatic, renal and cardiac antioxidant enzyme activities of healthy mice was investigated. The data provided evidence that they may play an important role as an endogenous antioxidant. Both acted as superoxide anion scavengers as well as general free radical scavengers ${ }^{18}$.

According to a published review, it was proposed that TQ affects all cancer hallmarks except "avoiding the immune system", which has not been investigated (in depth) to date. Peripheral blood contains a large pool of cells that perform a multitude of functions, and these cells can be used for diagnosis and treatment of many diseases as important effector immune cells. Circulating leukocytes include lymphocytes, neutrophils, esinophils, basophils, monocytes and other less abundant cell types ${ }^{19}$.
For that reason this work offers a preliminary data concerning the effect of TQ (compared to NSO) on the peripheral WBCs and lymphocytes in the HBP/DMBA model.

\section{MATERIAL AND METHODS:}

A total of one hundred and ten (120) male Syrian hamsters, aged 6-8 weeks, weighing 90-100grams, were purchased from the Central Animal House, Theodore Bilhars Research Institute, Cairo, Egypt. They were housed 5 animals/cage and provided water and standard food ad libitum.

This work was carried out at two phases, to evaluate the effect of Nigella sativa (NS) whole oil (NSO) *(phase A), thymoquinone** (TQ the active ingredient of NS (phase B), on total WBCs, total lymphocytes, MID, and granulocytes counts, in the well-known HCP/DMBA carcinogenesis model, in relation to the epithelial changes in each phase and between phases.

Phase A: NS oil group, (50 animals), where NSO was used alone, before-, with- or afterDMBA painting.

DMBA Sigma Aldrich Comp, Saint Louis, MO, USA

Thymoquinone was purchased from Sigma Aldrich Comp, Saint Louis, MO, USA.

Phase A: NSO group: (50 animals, where the oil was used alone, before-, with-, or after-DMBA painting.

Phase B: TQ group, (50 animals) where TQ was used alone, before-, with-, or after- the carcinogen (DMBA).

Ten (10) animals were used as untreated (negative) control group (G-I)

Ten (10) animals were painted with the carcinogen only 3 times /w/6weeks, served as positive controls (G-II).

*NSO, from Pharco Comp, Egypt 
NSO was given via an intra-gastric tube.

TQ was given through intraperitoneal injections (i.p.) in a dose of $0.1 \mathrm{mg} / \mathrm{kg}$ body weight, daily. TQ was dissolved in propylene glycol.

DMBA in a solution of $0.5 \%$ dissolved in heavy mineral oil, was painted with number 4 camel hair brush to the left cheek pouches only, 3 times per week.

\section{Treatment grouping (table 1):}

\section{Phase A: NSO}

Group Ai: NSO alone was given daily for 2 weeks (20 animals) via an intra-gastric tube, ten were sacrificed (Aia), and the other 10 were painted with the carcinogen alone for another 6 weeks (Aib).

Group Aii: both NSO (daily) plus DMBA were given for 3 times for 6 weeks (10 animals).

Group Aiii: NSO only (for 2 weeks, daily) then both NSO plus DMBA (3/wk./ 6 weeks) (10 animals).

Group Aiv: DMBA only for 6 weeks then NSO only for another 6 weeks (10 animals).

Phase B: TQ: (10 animals for each sub-group)

Group Bia: TQ was injected i.p. alone for 2 weeks, daily.

Group Bib: TQ for 2 weeks (as before), then DMBA only for 6 weeks.

Group Bii: Both TQ i.p., DMBA for 6 weeks.

Group Biii: TQ only (2wks) the both TQ and DMBA (for 6wks).

Group Biv: DMBA only for 6 weeks then TQ for another 6 weeks.

Blood analysis: before sacrificing, animals were anaesthetized by ether inhalation, then $2 \mathrm{ml}$. of blood sample was withdrawn (from the orbital sinus through the mesial angel of the eye) into a heparinized tube, immediately analyzed by an automatic count system (cell-DYN1700), Hematology Lab., University Hospital, Suez Canal University. The following differential picture was revealed,(due to lack of specific markers to hamster's blood cells at the time of the experiment): total WBCs, total lymphocytes, MID (indicating monocytes, basophils, and esinophils), and granulocytes (indicating polymorphonuclear leukocytes).

Data were analyzed using "One way ANOVA test" for each phase followed by LSD (Least Square Difference) test for multiple comparisons between different phases.

Histopathologic evaluation: animals were sacrificed by inhalation of an overdose of ether; both buccal pouches were surgically excised, fixed in $10 \%$ neutral buffer formalin and processed for routine $\mathrm{H} \& \mathrm{E}$ stain.

\section{RESULTS}

\section{Clinical observations:}

The overall health performance of all animals given NSO and TQ were better than those of control group. DMBA-treated animals showed one death, the rest were weak, lost weight, showed hair loss around the oral cavity, and skin eruptions at areas of hair loss that turned to be squamous cell carcinoma.

After one week of DMBA-painting a necrotic white material with fetid odor was coming out with the brush (indicating necrosis of the distal part of the painted pouches), and disappeared in one week, resulting in marked shortening of these pouches.

Much milder clinical features were encountered in animals given the two ingredients with- or after the carcinogen, while such clinical manifestations were delayed, for one week, in groups given the carcinogen after 2 weeks of either ingredient. However, neither deaths nor skin carcinomas were reported in the treated groups as seen in DMBAonly painted animals (G-II). 


\section{Histopathologic results: (table I):}

The hamster cheek pouches of the control group (G-I), exhibited the normal thin keratinized stratified squamous epithelium (st sq ep) of 2-4 cell thickness, with no rete ridges and free of inflammatory cells. The pouches of NSO, TQ, (G-Aia and G-Bia) animals were of normal appearance with slight hyperkeratinisation. The connective tissue was free of inflammatory cells in a loose lamina propria, with striated muscle layer in the submucosa.

DMBA-painted pouches (G-II) showed focal epithelial hyperplasia \& hyperkeratinisation with severe epithelial dysplastic changes as dropshaped rete ridges, basal cell hyperplasia, loss of their polarity, hyperchromatism, cellular\& nuclear pleomorphism, prominent nucleoli, loss of cellular adhesion, and abnormal mitotic figures (in the form of multinucleated epithelial cells). The connective tissue was more fibrous with moderate inflammatory infiltrate.
Mild epithelial dysplasia was seen in pouches of animals given NSO or TQ for 6 weeks) after the carcinogen was stopped (G-Aiv and G-Biv).

Same finding was found when NSO\&DMBA was given after NSO for 2 weeks (G-Aiii) and when TQ was given for $2 \mathrm{wks}$ followed by DMBA for 6wks (G-Bib).

\section{Blood leukocytes' results (tables II-VII):}

Table II: (the two ingredients alone for $2 \mathrm{wks}$ compared to G-I\& G-II).

There was a reduction in total WBCs\& lymphocyte counts, which was statistically significant, after 6 weeks of DMBA(G-II) compared to untreated group (G-I). While there was an elevation of total WBCs, in a statistical significant difference, after 2 weeks of either component (NSO and TQ) compared to G-II, no statistically significant difference with untreated group.

TABLE (I) Treatment grouping and main histopathologic findings:

\begin{tabular}{|l|l|l|}
\hline Groups & Treatment & Histopathologic changes \\
\hline G-I & Untreated control & $\begin{array}{l}\text { Thin keratinized surface epithelium (2-4 cell thickness), no } \\
\text { rete ridges \& no inflammatory cells. }\end{array}$ \\
\hline G-II & DMBA for 6 weeks & $\begin{array}{l}\text { Focal epithelial hyperplasia\& hyperkeratinisation, severe } \\
\text { epithelial dysplasia and moderate inflammatory cellular } \\
\text { infiltrate. }\end{array}$ \\
\hline G-Aia & NSO only for 2 weeks & Similar to control with slight hyperkeratinisation. \\
\hline G-Aib & NSO(2wks) then DMBA(6wks) & $\begin{array}{l}\text { Focal epithelial hyperplasia, severe epithelial dysplasia } \\
\text { and moderate inflammatory cellular infiltrate. }\end{array}$ \\
\hline G-Aii & Both NSO and DMBA $(6 \mathrm{wks})$ & Focal epithelial hyperplasia and moderate dysplasia. \\
\hline G-Aiii & NSO $(2 \mathrm{wks})$ then both DMBA\&NSO $(6 \mathrm{wks})$ & Focal epithelial hyperplasia and mild dysplasia. \\
\hline G-Aiv & DMBA then NSO (6wks) & Focal epithelial hyperplasia and mild dysplasia. \\
\hline G-Bia & TQ only for 2 weeks & Similar to control group. \\
\hline G-Bib & TQ (2wks) then DMBA & Focal epithelial hyperplasia and mild dysplasia. \\
\hline G-Bii & Both TQ and DMBA (6wks) & Focal epithelial hyperplasia and moderate dysplasia. \\
\hline G-Biii & TQ (2wks) then both DMBA and TQ $(6 \mathrm{wks})$ & Focal epithelial hyperplasia and mild dysplasia. \\
\hline G-Biv & DMBA then TQ (6wks $)$ & Focal epithelial hyperplasia and mild dysplasia. \\
\hline
\end{tabular}




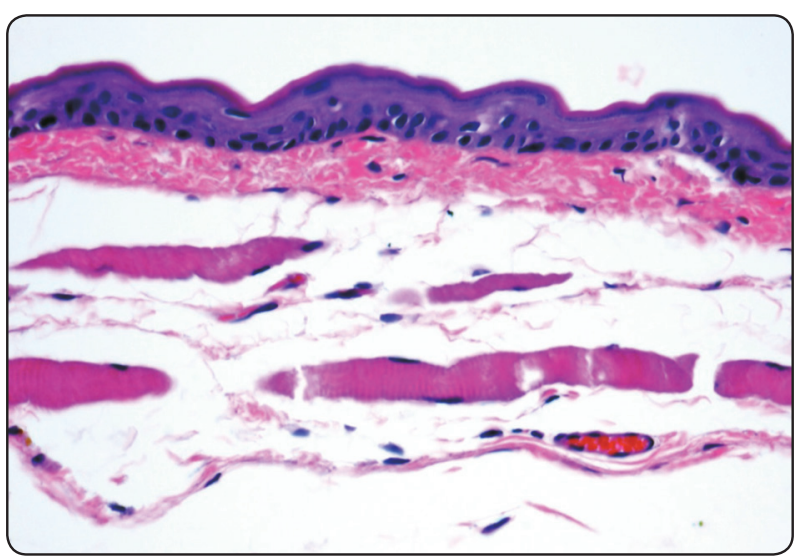

Fig. (1) A photomicrograph of histopathologic section from untreated control group, showing thin keratinized stratified squamous epithelium, covering connective tissue (free from inflammatory infiltrates), a layer of striated muscles and intact basement membrane (H\&E x20)

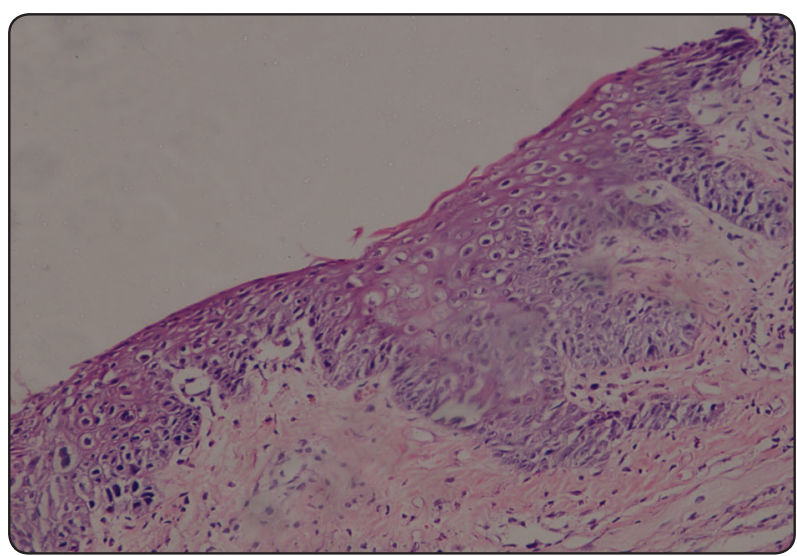

Fig. (3) A photomicrograph of histopathologic section from the group given DMBA for six weeks, showing severe epithelial dysplasia with drop shaped rete pegs and intact basement membrane. (H\&E x 10).

An elevation of total lymphocyte counts in NSO and TQ groups, which was statistically significant, as compared to G-I. It was elevated in a statistical significance difference with either component (NSO and TQ) as compared to G-II. No statistically significant difference in MID or granulocyte's counts with either component (NSO and TQ) as compared to G-I or G-II.

Table III: (DMBA for 6 wks then NSO or TQ for

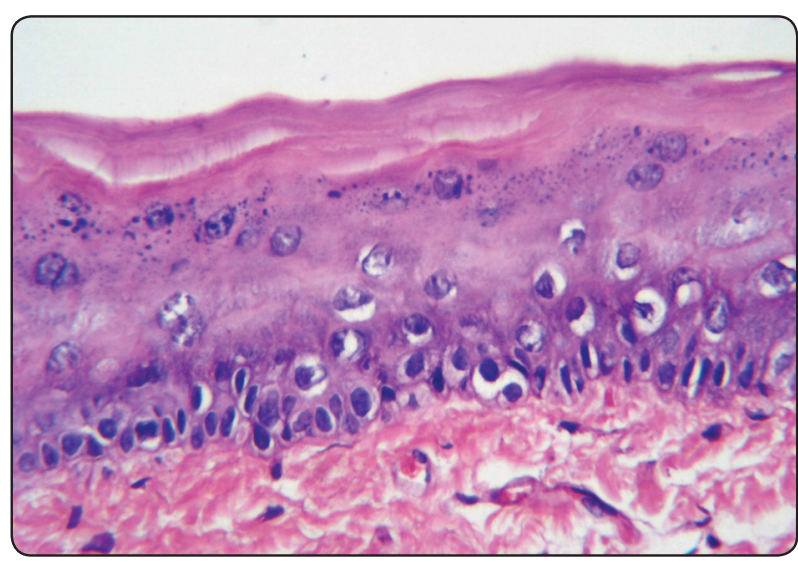

Fig. (2) A photomicrograph of histopathologic section from the group given DMBA (6weeks), followed by TQ (6wks), showing hyperplasia and mild epithelial dysplasia and intact basement membrane. (H\&E x 40)

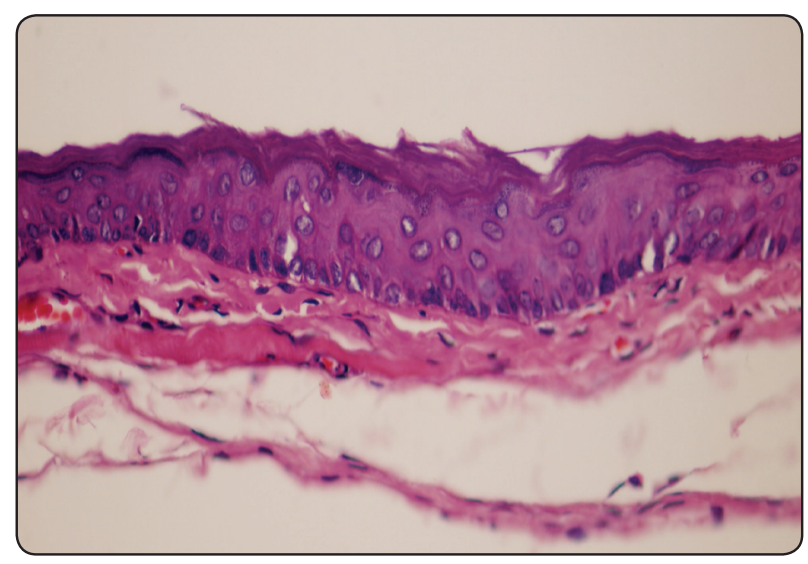

Fig. (4) A photomicrograph of histopathologic section from the group treated with NSO (2wks),followed by both DMBA and NSO (6wks), showing slight hyperplasia and hyperkeratinisation with mild epithelial dysplasia and intact basement membrane. (H\&E x20).

6wks as compared to G I). An elevation in WBCs, was statistically significant, after DMBA-painting for 6 weeks followed by TQ (G B-iii) as compared to NSO group (G-Aiv). While the elevation in lymphocyte count, was statistically significant, in TQ group compared to NSO and control groups. No statistically significant difference in MID or granulocytes' counts in all experimental groups compared to $\mathbf{G}-\mathbf{I}$. 
Table IV: (DMBA for 6 wks then NSO or TQ for 6wks as compared to G II).

An elevation of WBCs, in a statistically significant level, when TQ for 6 weeks was given after 6 weeks of DMBA (G-Biv), compared to G-II and NSO groups (G-Aiv).

While an elevation of lymphocytes' count was statistically significant when NSO or TQ were given for 6 weeks after DMBA (G-Aiv \&G-Biii), as compared to G-II. While its elevation was highly statistically significant in the TQ group compared to NSO group. No statistically significant difference in MID or granulocytes' counts between all groups.

Table V: (either component for 2 wks then DMBA for 6wks).

TABLE (II) Blood cell results in different groups (untreated, NSO and TQ as compared to untreated \& DMBA groups:

\begin{tabular}{|c|c|c|c|c|c|}
\hline Blood results & Dependant variable & Groups & Mean & $\begin{array}{l}\text { Standard } \\
\text { deviation }\end{array}$ & $\begin{array}{c}\text { Mean difference } \\
\text { (p value) }\end{array}$ \\
\hline \multirow{6}{*}{ WBC count(k/mL) } & \multirow{3}{*}{ Group-I } & Group-I & 5.52 & 1.32 & - \\
\hline & & Group Aia & 7.0 & 1.16 & 1.48 \\
\hline & & Group Bia & 7.3 & 1.66 & 1.78 \\
\hline & \multirow{3}{*}{ Group-II } & Group II & 3.54 & 0.84 & $1.98 *$ \\
\hline & & Group Aia & & & $3.5^{*}$ \\
\hline & & Group B ia & & & 3.94* \\
\hline \multirow{6}{*}{$\begin{array}{l}\text { Lymphocyte's count } \\
\qquad(\mathrm{k} / \mathrm{mL})\end{array}$} & \multirow{3}{*}{ Group-I } & Group-I & 3.54 & 0.829 & - \\
\hline & & Group Aia & 5.20 & 0.846 & $1.66^{*}$ \\
\hline & & Group Bia & 5.6 & 1.62 & $2.01 *$ \\
\hline & \multirow{3}{*}{ Group-II } & Group-II & 1.7 & 0.35 & $1.84 *$ \\
\hline & & Group Aia & & & $3.5^{*}$ \\
\hline & & Group Bia & & & $3.94 *$ \\
\hline \multirow{6}{*}{$\begin{array}{l}\text { MID cell's count } \\
\qquad(\mathrm{k} / \mathrm{mL})\end{array}$} & & Group-I & 1.22 & 0.449 & - \\
\hline & & Group Aia & 1.1 & 0.339 & 0.120 \\
\hline & & Group Bia & 1.04 & 0.241 & 0.66 \\
\hline & \multirow{3}{*}{ Group-II } & Group-II & 1.26 & 0.44 & 0.04 \\
\hline & & Group Aia & & & 0.16 \\
\hline & & Group Bia & & & 0.22 \\
\hline \multirow{6}{*}{$\begin{array}{c}\text { Granulocyte's count } \\
\qquad(\mathrm{k} / \mathrm{mL})\end{array}$} & \multirow{3}{*}{ Group-I } & Group-I & 0.76 & 0.241 & - \\
\hline & & Group Aia & 0.70 & 0.158 & 0.600 \\
\hline & & Group Bia & 0.62 & 0.192 & 0.140 \\
\hline & \multirow{3}{*}{ Group-II } & Group-II & 0.58 & 0.24 & 0.18 \\
\hline & & Group Aia & & & 0.12 \\
\hline & & Group Bia & & & 0.04 \\
\hline
\end{tabular}

* The mean difference is significant at $p<0.05$ level.

-WBC count: white blood cell count.

-MID cells: less frequently occurring (monocytes, esinophils, basophils and other precursor white cells).

-Group-I: untreated group

-G Aia: NSO for 2 weeks
-Group-II: DMBA only for 6 weeks

-G Bia: TQ for 2 weeks 
A reduction in WBCs and lymphocytes' counts was statistically significant when either component was given for 2 weeks followed by DMBA for 6weeks, as compared to G-I. \{Numerically, more reduction in lymphocytes' count was seen in NSO group compared to TQ, while was more elevated than in DMBA-only painted group (G-II)\}.

No statistically significant difference in MID counts between both components, however numerically their mean counts were reduced compared to $\mathbf{G} \mathbf{I}$.

Only reduction in granulocytes' count was statistically significant in TQ group compared to G-I (numerically their mean counts were reduced than in NSO group).

TABLE (III) Blood cells results in the groups given DMBA for 6 weeks then NSO (G-Aiv) or TQ (G-Biii) for 6 weeks as compared to untreated group (G-I):

\begin{tabular}{|c|c|c|c|c|c|}
\hline Blood & Dependant variable & Groups & Mean & Standard deviation & Mean difference \\
\hline \multirow{5}{*}{ WBC count $(\mathrm{k} / \mathrm{mL})$} & \multirow{2}{*}{ Group-I } & Group-I & 5.52 & 1.32 & - \\
\hline & & Group Aiv & 4.08 & 0.83 & 1.44 \\
\hline & \multirow{3}{*}{ Group Aiv } & Group Biii & 6.42 & 1.266 & 0.90 \\
\hline & & Group-I & & & 1.22 \\
\hline & & Group Biii & & & $2.34 *$ \\
\hline \multirow{5}{*}{$\begin{array}{l}\text { Lymphocyte's count } \\
\qquad(\mathrm{k} / \mathrm{mL})\end{array}$} & \multirow{3}{*}{ Group-I } & Group-I & 3.54 & 0.829 & - \\
\hline & & Group Aiv & 2.60 & 0.387 & 0.49 \\
\hline & & Group Biii & 5.04 & 0.80 & $1.5^{*}$ \\
\hline & \multirow{2}{*}{ Group Aiv } & Group-I & & & 0.49 \\
\hline & & Group Biii & & & $2.44 *$ \\
\hline \multirow{3}{*}{$\begin{array}{l}\text { MID cell's count }(\mathrm{k} / \\
\mathrm{mL})\end{array}$} & \multirow{3}{*}{ Group-I } & Group-I & 1.22 & 0.45 & - \\
\hline & & Group Aiv & 0.88 & 0.377 & 0.34 \\
\hline & & Group Biii & 0.86 & 0.261 & 0.36 \\
\hline \multirow{3}{*}{$\begin{array}{l}\text { Granulocyte's count } \\
\qquad(\mathrm{k} / \mathrm{mL})\end{array}$} & \multirow{3}{*}{ Group-I } & Group-I & 0.76 & 0.241 & - \\
\hline & & Group Aiv & 0.60 & 0.187 & 0.16 \\
\hline & & Group Biii & 0.52 & 0.217 & 0.24 \\
\hline
\end{tabular}

-Group-I: untreated group

-Group Biii: DMBA for 6 weeks then TQ for 6 weeks
-Group Aiv: DMBA for 6 weeks then NSO for 6 weeks

* The mean difference is significant at $p<0.05$ level. 
TABLE (IV) Blood cells results in groups treated with DMBA for 6 weeks then NSO (G-Aiv) or TQ (G-Biii) for 6 weeks as compared to DMBA group (G-II):

\begin{tabular}{|c|c|c|c|c|c|}
\hline Blood & Dependant variable & Groups & Mean & Standard deviation & Mean difference \\
\hline \multirow{5}{*}{ WBC count $(\mathrm{k} / \mathrm{mL})$} & \multirow{3}{*}{ Group II } & Group-II & 3.54 & 0.84 & - \\
\hline & & Group Aiv & 4.08 & 0.83 & 0.54 \\
\hline & & Group Biii & 6.42 & 1.27 & $2.88 *$ \\
\hline & \multirow{2}{*}{ Group Aiv } & Group-II & & & 0.54 \\
\hline & & Group Biii & & & $2.34 *$ \\
\hline \multirow{5}{*}{$\begin{array}{l}\text { Lymphocyte's count } \\
\qquad(\mathrm{k} / \mathrm{mL})\end{array}$} & \multirow{3}{*}{ Group-II } & Group-II & 1.7 & 0.35 & - \\
\hline & & Group Aiv & 2.64 & 0.387 & $0.90 *$ \\
\hline & & Group Biii & 5.04 & 0.81 & $3.34 *$ \\
\hline & \multirow{2}{*}{ Group Aiv } & Group-II & & & $0.90 *$ \\
\hline & & Group Biii & & & $2.44 *$ \\
\hline \multirow{3}{*}{$\begin{array}{l}\text { MID cell's count } \\
\qquad(\mathrm{k} / \mathrm{mL})\end{array}$} & \multirow{3}{*}{ Group-II } & Group-II & 1.26 & 0.44 & - \\
\hline & & Group Aiv & 0.88 & 0.38 & 0.380 \\
\hline & & Group Biii & 0.86 & 0.261 & 0.400 \\
\hline \multirow{3}{*}{$\begin{array}{l}\text { Granulocyte's count } \\
\qquad(\mathrm{k} / \mathrm{mL})\end{array}$} & \multirow{3}{*}{ Group-II } & Group-II & 0.58 & 0.241 & - \\
\hline & & Group Aiv & 0.60 & 0.187 & 0.02 \\
\hline & & Group Biii & 0.52 & 0.22 & 0.06 \\
\hline
\end{tabular}

-Group-II: DMBA only group (for 6 weeks)

-Group Biv: DMBA for 6 weeks then TQfor 6 weeks
-Group Aiv: DMBA for 6 weeks then NSO for 6weeks

* The mean difference is significant at $p<0.05$ level.

TABLE (V) Blood cells results between groups (both ingredients only for 2 weeks then DMBA for 6 weeks):

\begin{tabular}{|c|c|c|c|c|c|}
\hline Blood & Dependant variable & Groups & Mean & Standard deviation & Mean difference \\
\hline \multirow{3}{*}{ WBC count $(\mathrm{k} / \mathrm{mL})$} & & Group-I & 5.52 & 1.32 & - \\
\hline & Group-I & Group-A-ib & 3.14 & 0.63 & $2.38 *$ \\
\hline & & Group- B-ib & 3.58 & 1.55 & $1.94 *$ \\
\hline \multirow{3}{*}{$\begin{array}{l}\text { Lymphocyte's count } \\
\qquad(\mathrm{k} / \mathrm{mL})\end{array}$} & & Group-I & 3.54 & 0.829 & - \\
\hline & Group-I & Group- A-ib & 1.66 & 0.297 & $1.88 *$ \\
\hline & & Group-B-ib & 2.32 & 1.01 & $1.22 *$ \\
\hline \multirow{3}{*}{$\begin{array}{l}\text { MID cell's count } \\
\qquad(\mathrm{k} / \mathrm{mL})\end{array}$} & & Group-I & 1.22 & 0.499 & - \\
\hline & & Group- A-ib & 0.94 & 0.251 & 0.280 \\
\hline & & Group- B-ib & 0.84 & 0.568 & 0.380 \\
\hline \multirow{3}{*}{$\begin{array}{l}\text { Granulocyte's count } \\
\qquad(\mathrm{k} / \mathrm{mL})\end{array}$} & & Group-I & 0.76 & 0.241 & - \\
\hline & Group-I & Group- A-ib & 0.54 & 0.230 & 0.220 \\
\hline & & Group- B-ib & 0.42 & 0.1095 & $0.340 *$ \\
\hline
\end{tabular}

-Group-I: untreated group

-Group B-ib: TQfor 2 weeks then DMBA for 6 weeks
-Group A-ib: NSO for 2 weeks then DMBA for 6 weeks

* The mean difference is significant at $p<0.05$ level. 


\section{DISCUSSION}

The overall clinical performance of the animals given the two ingredients, and absence of deaths clearly indicate their beneficial activities as antiinflammatory, detoxifying and mostly immunestimulatory agents. From the well-known HCPE/ DMBA model for OSCC induction, after 6 weeks of DMBA painting, shortening of the painted pouches and severe epithelial dysplasia \&/or carcinoma in situ, can be recognized ${ }^{(3,4)}$, as seen in the present work.

From the well-known HCPE/DMBA model for induction of OSCC, from the $6^{\text {th }}$ week of DMBA painting, shortening of the painted pouches and severe epithelial dysplasia \&/or carcinoma in situ, can be recognized..$^{(3,4,20,21,22)}$

The present results of severe dysplasia in $\mathbf{G}$ II accompanied with reduction of total WBCs \& lymphocytes counts in a statistically significant level, compared to untreated control group. This indicates the high local \&systemic toxicity of DMBA for that animal model. Although no statistical significant differences in other peripheral leukocytes (MID $\&$ granulocytes), there was numerical reduction in granulocytes' count compared to untreated group. Contrary to that finding (of reduced immune cells) is the study, which had evaluated the immune status of 16 untreated patients with OSCC in comparison with healthy donors ${ }^{23}$.

As well, previous studies had reported a progressive increase in the mean helper/suppressor cell ratio with increased tumor stage in 80 previously untreated $\mathrm{H} \& \mathrm{~N}$ cancer patients, and was significantly elevated among patients with cancer as a group and in patients with stages III\&IV as compared to 40 normal subject ${ }^{24}$. Both results (of increased lymphocytes, leukocytes and helper/ suppressor cell ratio in cancer patients) may be due to the small number of patients (in the first work), or due to reduced activity of cells, or due to different sites and/or stage of the tumors between patients. In agreement with the present results another researchers who found that total T-cell counts were reduced in twenty-two patients with the greatest reduction occurring in patients with hypopharyngeal tumors and/or stage IV disease. Helper to suppressor ratio was within normal for all patients, however specific site variances were 23 detected as well as in stage III disease ${ }^{25}$.

Another study had concluded that in patients with head and neck cancer, decreased local and regional antitumor responses are associated with a deficiency of functional cytotoxic effector cells rather than an increase in suppressor T lymphocytes. Freshly isolated tumor-infiltrating lymphocytes were deficient in $\mathrm{CD} 4+\mathrm{T}$ cells in comparison with lymph node lymphocytes and peripheral blood lymphocytes ${ }^{26}$. Furthermore, in agreement with reduced WBCs\& lymphocytes (in the present work after 6wks of DMBA), was seen in another work , made to study the relation of total lymphocyte's count and blastogenesis in 70 patients with OSCC. The results correlated with clinical stage, tumor size, lymph node involvement, tumor differentiation, lymphoreticular responses and outcome during a one year follow-up period.

Although absolute lymphocyte counts and T-cell population were reduced in primary stage of the disease, the functional capacity of isolated lymphocytes to undergo blast formation was retained. This blastogenesis activity showed a significant impairment only when the tumor was well established and disseminated beyond its primary $\operatorname{sit}^{27}$.

It was declared that the $\mathrm{T}$ cell subsets distributions in OSCC patients tend to show an immunosuppressive $\mathrm{T}$ cell immune status when compared to healthy people. Although OSCC triggers reactions in cell-mediated immunity, the "fighting" ability is not sufficient and the negative regulating T cells are stronger ${ }^{28}$.

Of interest is the ability of the proposed immuneenhancers NSO or TQ, to suppress one of the important immune responses as the hypersensitivity 
response.it was reported that intraperitoneal administration of NSO, inhibited the Th2 type immune response in rats by preventing inflammatory cell infiltration and pathologic lesions in the lungs. It was concluded that NSO exhibited a significant reduction in all markers of allergic inflammation mainly by inhibiting delayed hypersensitivity and T-cell proliferation in the spleen ${ }^{29}$. That it may explain the numerical reduction in MID, i.e. basophils, esinophils and monocyte counts in NSO\&TQ groups when given for $2 \mathrm{wks}$ as compared to both control groups (G I,GII) (table II) however, TQ showed more reduction than NSO.

In the present work NSO and TQ alone for 2 weeks, had resulted in normal appearing cheek pouch epithelium, with slight increase in the keratin layer, which may correlate with a positive differentiation effect of these ingredients on the cheek epithelial cells. Same results were recorded that hamsters treated with thymoquinone alone showed no significant differences in histological features as compared to control hamsters ${ }^{30}$.

Each one of the tested ingredients given for 2wks (G-Aia, and -Bia) had resulted in increase of total WBCs in a non-statistical significant compared to control group, however they were increased numerically, with the TQ showing higher numbers (table II). Total lymphocyte counts, on the other hand showed statistical significant elevation when NSO or TQ were given alone. Again TQ showed increased mean number compared to NSO group. This observation is in agreement with researchers who stated that the volatile oil of NS resulted in a rise of peripheral lymphocytes and monocytes in the experimental group ${ }^{17}$.

Another study, showed that NS seeds enhanced by $55 \%$ the ratio between helper and suppressor $\mathrm{T}$ cells, and a $30 \%$ average enhancement of the natural killer cell activity, in human volunteers ${ }^{31}$.A finding that enforce stimulation of the effector immune cells by NS seeds (the origin of NSO and TQ). Another study reported a significant enhancement of Candida albicans ingestion by peritoneal macrophages in the tested mice (fed with black seed enriched food)), as compared with control mice on normal $\operatorname{diet}^{32}$. Moreover, NS was found to enhanced the production of IL-3 by human lymphocytes (i.e. stimulated their activity) . also it was reported that when NS was cultured with pooled allogeneic cells or without any added stimulator, however it did not enhance or suppress IL-2 secretion by mitogenactivated peripheral blood mononuclear cells (PBMC). Meanwhile they reported an increase of IL- $1 \beta$, suggesting an effect on macrophages ${ }^{33}$.

In the present study, NSO or TQ given at different sequences with the carcinogen(table I) had resulted in mild/ moderate epithelial dysplasia, accompanied by increased total WBCs\& lymphocytes counts, strongly suggests that both ingredients have protective activities against the DMBA toxic effect.

The mechanism by which both NSO \&TQ are anti-inflammatory agents through inhibition of cyclooxygenase and 5-lipoxygenase pathways of arachidonate metabolism in rat peritoneal leukocytes was explained. It was found that TQ was about ten times more potent than $\mathrm{NSO}^{34}$. Furthermore, TQ was found to protect against chromosomal aberration, a study reported that TQ supplementation in the drinking water of mice (daily intake) before-, during- or after exposure to benzo- $(a)$-pyrene [ $\mathrm{B}(\mathrm{a}) \mathrm{P}]$, significantly reduced the frequencies of chromosomal aberrations and damaged bone marrow cells as compared to the highly clastogenic activity of $\mathrm{B}(\mathrm{a}) \mathrm{P}$ alone ${ }^{35}$.

Another study had demonstrated that a radioprotective effect by TQ on the immune system, related to its anti-inflammatory and antioxidant capacities. TQ relieved the immune system damage induced by reducing immune dysfunction through reducing $\mathrm{T}$ cells apoptosis either directly or by weakening the thymus destruction (the site of T cell maturation $)^{36}$.

The toxic effect of DMBA is further confirmed, in the present work, when it was painted for $6 \mathrm{wks}$ after 
pretreatment with NSO or TQ for 2wks (G-Aib and G-Bib). A reduction of total WBCs\& lymphocytes as well as granulocyte's count in a statistical significant level ( especially with TQ group) as compared to G-I. Some reports showed that DMBA has suppressed B and T-cell mitogenesis, decreased natural killer cell activity, as well as decreased neutrophils and lymphocytes' levels ${ }^{(37 \& 38)}$.

Locally, severe epithelial dysplasia was seen when DMBA was painted for 6 wks after pretreatment with NSO (G-Aib), while was reverted to mild dysplasia when TQ preceded DMBA (G-Bib), i.e. TQ possesses more protective effect than NSO, against the DMBA insult. This finding was recorded. Some researchers explained their results as TQ could restrain proliferation and promote apoptosis of human cancer cell lines $\left({ }^{39},{ }^{40} \mathbf{Q}^{41}\right)$.

TQ effect was documented in other models, where the results indicated the high potentiality of TQ as a powerful chemo-preventive agent against benzo (a) pyrene-induced forestomach tumors in mice. Furthermore, it reduced the incidence and multiplicity of methylcholanthrene- induced fibrosarcoma in female Swiss albino mice by $70 \%$ and $67 \%$, respectively. They postulated that TQ mode of action may be through its antioxidant and anti-inflammatory activities, as well as enhancement of detoxification processes ${ }^{(42 \& 43)}$.

TQ inhibitory effect was tested in other models, when it had demonstrated that TQ induced apoptosis of human colon cancer cells ${ }^{14}$, further study documented by other researchers. They demonstrated that TQ was able to inhibit cell proliferation, reduce cell viability and induce apoptosis. They used a mouse xenograft model and demonstrated that combination of TQ and cisplatin were well tolerated, and significantly reduced tumor volume and weight without additional toxicity to the mice. TQ was found to down regulate NF- $\varkappa \mathrm{B}$ expression which may explain its various cellular activities, and this activity may prove useful in overcoming cisplatin resistance from NF- $x \mathrm{~B}$ over expression ${ }^{44}$.
Various studies concluded that the NSO, extracts, and their active ingredients, in particular, thymoquinone, possess analgesic and antiinflammatory effects, supporting the common folk perception of NS as a potent analgesic and antiinflammatory agent. Many protective properties are attributed to the radical scavenging activity as well as an interaction with numerous molecular targets involved in inflammation, including proinflammatory enzymes and cytokines ${ }^{45}$.

The toxic and mutagenic effect of DMBA became significantly less effective when NSO was given for 2 wks before- and continued with DMBA for $6 \mathrm{wks}$ (G-Aiii) where mild epithelial dysplasia was seen. Same observation was reported i.e. where it was found that continued NSO intake resulted in better protection from the DMBA effect. This protection could be through decreasing DNA damage ${ }^{46}$.

In agreement with that hypothesis, it was found that NS had decreased DNA damage and thereby prevents initiation of carcinogenesis in rat's colonic tissue secondary to exposure to toxic agents as azoxymethane $^{(47 \& 48)}$. It had been reported that NS seeds emulsion showed a preventive effect against chromosomal breakage in patients with Down syndrome, which may decrease the risk of malignant diseases $^{49}$.

In the present study, when DMBA was painted for $6 \mathrm{wks}$ followed by either NSO or TQ for $6 \mathrm{wks}$, had resulted in mild epithelial dysplasia (G Aiv \&G Biii), i.e. regression of severe dysplasia to mild dysplasia. The same observation, with NSO had described ${ }^{41}$. This finding indicates a promising chemotherapeutic activity of NSO and TQ, which could be due to a cytotoxic effect on mutated cells, it was reported that a cytotoxic activity of NS purified components against many tumor cell lines, or could be due to enhancement of the detoxification process $^{50}$.

The blood results of the present work showed an increase of WBCs \&lymphocytes' count in a statistical significant level, when TQ followed 
DMBA (G-Biii) as compared to NSO (G-Aiv) or DMBA-only group (G-II). Histologically, mild dysplasia resulted from such treatment. A finding that strengthens the immunomodulatory effect of TQ. This observation could be confirmed by the findings where TQ cytotoxicity was found to be effective against tumor cell lines with little effect against lymphocytes. Another work studied the antitumor activities of the active principle of NS seeds against Ehrlich ascites sarcoma (EAC), Dalton's lymphoma ascites and sarcoma-180 cells. In vitro cytotoxicity results showed $50 \%$ cytotoxicity to all cells with little activity against lymphocytes ${ }^{51}$. Later a study evaluated the effect of NSO, nigellone and TQ on the formation of 5-lipoxygenase (5-LO) products from PMNLs. The study found that NSO produced a concentration-dependant inhibition of 5-LO products and 5-HETE production. Whereas nigellone produced concentration-related inhibition of 5-HETE production, while TQ inhibited 5-LO products and 5-HETE production ${ }^{16}$.Furthermore, it was found that oral NS grains had protected rats against methylnitrourea ( $\mathrm{MNU}$ )-induced oxidative stress and carcinogenesis by $80 \%$ while when combined with honey showed $100 \%$ protection $^{52}$.

Although both ingredients given for $2 \mathrm{wks}$, in the present work, had led to non-statistical significant difference in total WBCs, the total lymphocytes was increased in a statistically significant level when NSO or TQ were given for $2 \mathrm{wks}$.

The apparent elevated mean numbers of WBCs\& lymphocytes with the two tested components, in the present work, together with milder epithelial dysplastic changes, would reflect a dual role in that model. One is local at the epithelial level, and the other is systemic through possible modulation of effector peripheral blood cell activities (cytotoxic lymphocytes, natural killer cells or macrophages), rather than just increasing their number. It was documented that treatment of mice with NS improved both physiological and structural changes of peripheral blood cells induced by carbon tetrachloride $(\mathrm{CCL} 4)^{53}$.Lymphokines are known to be essential in modulating the immune cells function. A study concluded that lymphocytes responded to analogous tumor cells only if IL-2 was added to the cultures. However, IL-2 alone induced some cell proliferation, which was not comparable to that observed in response to IL-2 and tumor cells ${ }^{54}$. Later on another work studied the immunomodulatory effect of NS \&its fractionated proteins. It was found that large quantities of IL-1 $\beta$ were secreted by whole NS in culture medium with non-activated peripheral blood mononuclear cells (PBMC), and with allogeneic cells. Fractionated NS was less effective when compared with whole NS proteins. Stimulatory effect of whole NS and fractionated proteins was also noticed on the production of TNF- $\alpha$ either using non-activated or mitogen activated cells ${ }^{30}$.

From the present work, the mild epithelial dysplasia seen when TQ (G-Biii) was given after DMBAmay be due to the cytotoxic effect of TQ on the mutated cells, comparable to another report, which investigated the TQ-induced cytotoxicity using different malignant cell lines using a proliferation (MTT assay) and apoptosis assays. COS31/rCDDP resistant cells were the most sensitive cell line to TQ, while MDCK cells were the least sensitive ${ }^{13}$. TQ (25 micro M) induced apoptosis of COS31 cells 6 hours after treatment and decreased the number of COS31 cells in S-phase and increased cells in G1-phase, indicating cell cycle arrest at G1. These results suggested that TQ works on cancer cells through apoptosis and cell cycle arrest. Noncancerous cells were relatively resistant to TQ ${ }^{(13)}$. Furthermore, a study showed that TQ inhibited the proliferation of a panel of human colon cancer cells, without exhibiting cytotoxicity to normal human intestinal cell line. Researchers revealed that apoptotic cell death was induced via the generation of reactive oxygen species ${ }^{55}$.

The promising preventive and therapeutic effects of TQ may be explained as described by a work , in which the researchers postulated that TQ may have potential in treatment of myeloid leukemia and 
other cancers, through suppression of TNF-induced $\mathrm{Nf}-\mathrm{kB}$ activation, in a dose- and time-dependant manner. TQ also down-regulated the expression of important NF- $x \mathrm{~B}$-regulated antiapoptotic, antiproliferative and angiogenic gene products ${ }^{\mathbf{5 6}}$. These activities could explain the protective and therapeutic effects of TQ in that model.

However, the statistical significant presentation of important peripheral immune cells in the present work, could be related to increased activity rather than increased number of these effector cells. As previously suggested that in patients with cancer, leukocyte inhibitory factor production was consistently, significantly impaired and directly related to the levels of T4-positive (helper/ inducer) lymphocytes ${ }^{21}$. A study found that human granulocyte colony-stimulating factor (hGCSF) hastened the recovery of peripheral neutrophils counts in golden hamsters made leukopenic by prior treatment with cyclophosphamide. Daily treatment with hGCSF made neutropenic hamsters resistant to lethal infection with i.p.injection of Staphylococcus aureus. This protective effect was associated with increased peritoneal neutrophils counts and decreased positive peritoneal bacterial cultures after $24 \mathrm{~h}$ of treatment ${ }^{57}$.

In a review, it was stated that a variety of non-hematopoietic malignant tumors have been demonstrated to secrete granulocyte colonystimulating factor (G-CSF) in amounts large enough to cause a significant systemic hematopoietic effect. G-CSF was reported to be secreted by nonhematopoietic tumor cells, as bladder cancer cells ${ }^{58}$, and anaplastic carcinoma of the pancreas ${ }^{59}$. It was found to activate neutrophil function in hamsters as well ${ }^{54}$.

From the present findings, it is clear that the effect of both tested ingredients was beneficial when they were given before-, continued-, or given after the carcinogen.

\section{CONCLUSION:}

DMBA for 6 weeks, resulted in severe epithelial dysplasia and significant reduction of circulating peripheral WBCs\& lymphocytes either alone or when given after their marked elevation after each of the ingredients were given for $2 \mathrm{wks}$.

At the local level, TQ showed the best chemoprotective \& chemotherapeutic effects for the chemically-induced malignant transformation in that model, whether given before-, with-, or after 6wks of DMBA.

NSO showed protective effect when given before- and continued with the carcinogen.

At the blood level, NSO or TQ alone showed elevation of total lymphocytes count in a statistically significant level, compared to DMBA, or control groups.

Both showed elevation of WBCs which was statistically significant as compared to DMBA group.

Larger doses and longer treatment periods are recommended to be tried in higher animal models in a step to use them in humans.

\section{ACKNOWLEDGMENT:}

We sincerely thank Dr./Nashwa Mohamed Yhiea; Lecturer of Mathematical Statistics, Faculty of Science, Suez Canal University. She helped much in all statistical work of that study with great patience and friendship.

\section{REFERENCES}

1. Siegel, R.L., K.D. Miller, and A. Jemal, Cancer statistics, 2015. CA Cancer J Clin, 2015. 65(1): p. 5-29.

2. Lopez, A.D., Mathers CD, Ezzati M, Jamison DT, Murray CJ., Global and regional burden of disease and risk factors, 2001: systematic analysis of population health data. Lancet, 2006. 367(9524): p. 1747-57.

3. Salley, J.J., Experimental carcinogenesis in the cheek pouch of the Syrian hamster. J Dent Res, 1954. 33(2): p. 253-62. 
4. Hassan, M.M.,Shklar G., Solt D., Szabo G., Acute effect of DMBA application on mitotic activity of hamster buccal pouch epithelium. Oral Surg Oral Med Oral Pathol, 1985. 59(5): p. 491-8.

5. Shklar, G., Development of experimental oral carcinogenesis and its impact on current oral cancer research. J Dent Res, 1999. 78(12): p. 1768-72.

6. Nagini, S., , Letchoumy PV., TV., Cr R., Of humans and hamsters: a comparative evaluation of carcinogen activation, DNA damage, cell proliferation, apoptosis, invasion, and angiogenesis in oral cancer patients and hamster buccal pouch carcinomas. Oral Oncol, 2009. 45(6): p. e31-7.

7. Cai, Y., Luo Q, Sun M, Corke H., Antioxidant activity and phenolic compounds of 112 traditional Chinese medicinal plants associated with anticancer. Life Sci, 2004. 74(17): p. 2157-84.

8. Salih, B., T. Sipahi, and E.O. Donmez, Ancient nigella seeds from Boyali Hoyuk in north-central Turkey. J Ethnopharmacol, 2009. 124(3): p. 416-20.

9. El-Fatatry, H.M., Isolation and structure assignment of an antimicrobial principle from the volatile oil of Nigella sativa L. seeds. Pharmazie, 1975. 30(2): p. 109-11.

10. Gali-Muhtasib, H., A. Roessner, and R. Schneider-Stock, Thymoquinone: a promising anti-cancer drug from natural sources. Int J Biochem Cell Biol, 2006. 38(8): p. 1249-53.

11. Gholamnezhad, Z., Boskabady M.H, and. Hosseini M, Effect of Nigella sativa on immune response in treadmill exercised rat. BMC Complement Altern Med, 2014. 14: p. 437 .

12. Burits, M. and F. Bucar, Antioxidant activity of Nigella sativa essential oil. Phytother Res, 2000. 14(5): p. 323-8.

13. Shoieb, A.M., Elgayyar M, Dudrick PS, Bell JL, Tithof PK., In vitro inhibition of growth and induction of apoptosis in cancer cell lines by thymoquinone. Int J Oncol, 2003. 22(1): p. 107-13.

14. Gali-Muhtasib H, Diab-Assaf M, Boltze C, Al-Hmaira J, Hartig R, Roessner A, Schneider-Stock R. Thymoquinone extracted from black seed triggers apoptotic cell death in human colorectal cancer cells via a p53-dependent mechanism. Int J Oncol, 2004. 25(4): p. 857-66.

15. Hajhashemi, V., A. Ghannadi, and H. Jafarabadi, Black cumin seed essential oil, as a potent analgesic and antiinflammatory drug. Phytother Res, 2004. 18(3): p. 195-9.
16. El-Dakhakhny, M., Madi NJ, Lembert N, Ammon HP. Nigella sativa oil, nigellone and derived thymoquinone inhibit synthesis of 5-lipoxygenase products in polymorphonuclear leukocytes from rats. J Ethnopharmacol, 2002. 81(2): p. 161-4.

17. Islam, S.N.,Begum P, Ahsan T, Huque S, Ahsan M. Immunosuppressive and cytotoxic properties of Nigella sativa. Phytother Res, 2004. 18(5): p. 395-8.

18. Mansour, M.A., Nagi MN, El-Khatib AS, Al-Bekairi AM.Effects of thymoquinone on antioxidant enzyme activities, lipid peroxidation and DT-diaphorase in different tissues of mice: a possible mechanism of action. Cell Biochem Funct, 2002. 20(2): p. 143-51.

19. Schneider-Stock R, Fakhoury IH, Zaki AM, El-Baba CO, Gali-Muhtasib HU.Thymoquinone: fifty years of success in the battle against cancer models. Drug Discov Today, 2014. 19(1): p. 18-30.

20. Abd El-Latif GA.: "Effect of thymoquinone and polythymoquinone on chemically-induced oral epithelial dysplasia: Experimental study". Ph.D. thesis, Faculty of Dentistry, Suez Canal Univ., 2008

21. Abd El-Aziz DMM: "Chemopreventive effect of green tea on 9, 12 dimethylbenz-(a)-anthracene (DMBA)-induced hamster buccal pouch carcinogenesis". M.Sc. thesis, Faculty of Dentistry, Suez Canal Univ., 2008

22. Al-Jawfi KAM, Hassan MMA, and El-Gohary AM: Expression of p53 following Nigella sativa oil treatment in DMBA-induced hamster buccal pouch carcinogenesis. Suez Canal Univ Med J; 2008b. 11(1):p. 81-8.

23. Saranath, D., Mukhopadhyaya R, Rao RS, Fakih AR, Naik SL, Gangal SG. Cell-mediated immune status in patients with squamous cell carcinoma of the oral cavity. Cancer, 1985. 56(5): p. 1062-70.

24. Wolf, G.T.,Lovett EJ 3rd, Peterson KA, Beauchamp ML, Baker SR. Lymphokine production and lymphocyte subpopulations in patients with head and neck squamous carcinoma. Arch Otolaryngol, 1984. 110(11): p. 731-5.

25. Strome, M., Clark JR, Fried MP, Rodliff S, Blazar BA.Tcell subsets and natural killer cell function with squamous cell carcinoma of the head and neck. Arch Otolaryngol Head Neck Surg, 1987. 113(10): p. 1090-3.

26. Snyderman CH, Heo DS, Johnson JT, D’ Amico F, Barnes L, Whiteside TL, Functional and phenotypic analysis of lymphocytes in head and neck cancer. Arch Otolaryngol Head Neck Surg, 1991. 117(8): p. 899-905. 
27. Das, S.N., N.N. Khanna, and S. Khanna, In vivo and in vitro observation of cellular immune parameters in squamous cell carcinoma of the oral cavity and its correlation with tumor load and prognosis. Cancer Invest, 1986. 4(3): p. 207-16.

28. Wang C., Liu S.X., Wang G. , Hua-Wei Liu H.W., Yuan X.H.,Hu M., Transformations of peripheral $\mathrm{T}$ cell subset distributions in oral cancer patients and the effect of P53 gene therapy in a short time. Int J Clin Exp Pathol, 2016. 9(3): p. 3889-3897.

29. Shahzad M, Yang X, Raza Asim MB, Sun Q, Han Y, Zhang F, Cao Y, Lu S. Black seed oil ameliorates allergic airway inflammation by inhibiting T-cell proliferation in rats. Pulm Pharmacol Ther, 2009. 22(1): p. 37-43.

30. Rajkamal G, Suresh K, Sugunadevi G, Vijayaanand MA, Rajalingam K., Evaluation of chemopreventive effects of Thymoquinone on cell surface glycoconjugates and cytokeratin expression during DMBA induced hamster buccal pouch carcinogenesis. BMB Rep, 2010. 43(10): p. 664-9.

31. El-Kadi, A. and O. Kandil. Effect of Nigella sativa (the black seed) on immunity. in Proceeding of the 4th International Conference on Islamic Medicine, Kuwait. Bull Islamic Med. 1986.

32. Ali, B. and Erwa H., Effect of Nigella sativa on ingestion ability of mice peritoneal macrophages. Saudi Pharm. J, 1993. 1: p. 18

33. Haq A, Lobo PI, Al-Tufail M, Rama NR, Al-Sedairy ST. Immunomodulatory effect of Nigella sativa proteins fractionated by ion exchange chromatography. Int J Immunopharmacol, 1999. 21(4): p. 283-95.

34. Houghton, P.J., Zarka R, de las Heras B, Hoult JR., Fixed oil of Nigella sativa and derived thymoquinone inhibit eicosanoid generation in leukocytes and membrane lipid peroxidation. Planta Med, 1995. 61(1): p. 33-6.

35. Badary, O.A., Abd-Ellah MF, El-Mahdy MA, Salama SA, Hamada FM .Anticlastogenic activity of thymoquinone against benzo(a)pyrene in mice. Food Chem Toxicol, 2007. 45(1): p. 88-92.

36. Guida MS, Abd El-Aal A, Kafafy Y, Salama SF, Badr BM, Badr G.,Thymoquinone Rescues T Lymphocytes from Gamma Irradiation-Induced Apoptosis and Exhaustion by Modulating Pro-Inflammatory Cytokine Levels and PD-1, Bax, and Bcl-2 Signaling. Cell Physiol Biochem, 2016. 38(2): p. 786-800.
37. Miyata M, Furukawa M, Takahashi K, Gonzalez FJ, Yamazoe Y.Mechanism of 7,12-dimethylbenz[a]anthraceneinduced immunotoxicity: role of metabolic activation at the target organ. Jpn J Pharmacol, 2001. 86(3): p. 302-9.

38. Galvan, N., Page TJ, Czuprynski CJ, Jefcoate CR., Benzo(a)pyrene and 7,12-dimethylbenz(a)anthrecene differentially affect bone marrow cells of the lymphoid and myeloid lineages. Toxicol Appl Pharmacol, 2006. 213(2): p. 105-16.

39. Brown, R.K.,Wilson G, Tucci MA, Benghuzzi HA. The effects of thymoquinone and Doxorubicin on leukemia and cardiomyocyte cell lines. Biomed Sci Instrum, 2014. 50: p. 391-6.

40. Chu SC, Hsieh YS, Yu CC, Lai YY, Chen PN., Thymoquinone induces cell death in human squamous carcinoma cells via caspase activation-dependent apoptosis and LC3II activation-dependent autophagy. PLoS One, 2014. 9(7): p. e101579.

41. Sutton, K.M., Greenshields A.L., and Hoskin D.W., Thymoquinone, a bioactive component of black caraway seeds, causes G1 phase cell cycle arrest and apoptosis in triple-negative breast cancer cells with mutant p53. Nutr Cancer, 2014. 66(3): p. 408-18.

42. Badary OA, Al-Shabanah OA, Nagi MN, Al-Rikabi AC, Elmazar MM. Inhibition of benzo(a)pyrene-induced forestomach carcinogenesis in mice by thymoquinone. Eur $\mathrm{J}$ Cancer Prev, 1999. 8(5): p. 435-40.

43. Badary, OA. and Gamal El-Din AM., Inhibitory effects of thymoquinone against 20-methylcholanthrene-induced fibrosarcoma tumorigenesis. Cancer Detect Prev, 2001. 25(4): p. 362-8.

44. Jafri SH, Glass J, Shi R, Zhang S, Prince M, Kleiner-Hancock $\mathrm{H}$. Thymoquinone and cisplatin as a therapeutic combination in lung cancer: In vitro and in vivo. J Exp Clin Cancer Res, 2010. 29(1): p. 29-87.

45. Amin, B. and Hosseinzadeh H., Black Cumin (Nigella sativa) and Its Active Constituent, Thymoquinone: An Overview on the Analgesic and Anti-inflammatory Effects. Planta Med, 2016. 82(1-2): p. 8-16.

46. Hassan, MMA.: "Nigella sativa extract and dysplasiachemically-induced in the hamster cheek pouch epithelium”. Proc Am Acad Oral Path., 1985 39: 19(A).

47. Al-Johar D, Shinwari N, Arif J, Al-Sanea N, Jabbar AA, El-Sayed R, Mashhour A, Billedo G, El-Doush I, Al-Saleh I., Role of Nigella sativa and a number of its antioxidant 
constituents towards azoxymethane-induced genotoxic effects and colon cancer in rats. Phytother Res, 2008. 22(10): p. 1311-23.

48. Kapoor, S., Emerging clinical and therapeutic applications of Nigella sativa in gastroenterology. World J Gastroenterol, 2009. 15(17): p. 2170-1.

49. El-Dahtory, F.A., the protective effect of nigella sativa seeds against mitomycin-c induced chromosomal breakage in down syndrome lymphocyte cultures. journal of medicine \& biomedical sciences, 2010(2). ISSN: 2078-0273.

50. Worthen, D.R., Ghosheh O.A., and Crooks P.A., The in vitro anti-tumor activity of some crude and purified components of blackseed, Nigella sativa L. Anticancer Res, 1998. 18(3a): p. 1527-32.

51. Salomi, N.J., et al., Antitumour principles from Nigella sativa seeds. Cancer Lett, 1992. 63(1): p. 41-6.

52. Mabrouk GM, Moselhy SS, Zohny SF, Ali EM, Helal TE, Amin AA, Khalifa AA. Inhibition of methylnitrosourea (MNU) induced oxidative stress and carcinogenesis by orally administered bee honey and Nigella grains in Sprague Dawely rats. Journal of experimental \& clinical cancer research: CR, 2002. 21(3): p. 341-6.

53. Essawy, A.E. Hamed SS, Abdel-Moneim AM AbouGabal AA.and Alzergy AA., Role of black seeds (Nigella sativa) in ameliorating carbon tetrachloride induced haematotoxicity in Swiss albino mice. Journal of Medicinal Plants Research, 2010. 4(19): p. 1977-1986.
54. Cozzolino F., Torcia M., Carossino AM., Giordani R., Selli C.,Talini G., Reali E., Novelli A.,Pistoria V.,Ferrarini M., Characterization of cells from invaded lymph nodes in patients with solid tumors. Lymphokine requirement for tumor-specific lymphoproliferative response. The Journal of experimental medicine, 1987. 166(2): p. 303-318.

55. El-Najjar N, Chatila M, Moukadem H, Vuorela H, Ocker M, Gandesiri M, Schneider-Stock R, Gali-Muhtasib H. Reactive oxygen species mediate thymoquinone-induced apoptosis and activate ERK and JNK signaling. Apoptosis, 2010. 15(2): p. 183-95.

56. Sethi, G., Ahn KS, andAggarwal BB., Targeting nuclear factor-kappa B activation pathway by thymoquinone: role in suppression of antiapoptotic gene products and enhancement of apoptosis. Mol Cancer Res, 2008. 6(6): p. 1059-70.

57. Cohen, A.M., Hines DK., Korach ES., AND Ratzkin BJ., In vivo activation of neutrophil function in hamsters by recombinant human granulocyte colony-stimulating factor. Infect Immun, 1988. 56(11): p. 2861-5.

58. Tachibana, M. and Murai M., G-CSF production in human bladder cancer and its ability to promote autocrine growth: a review. Cytokines Cell Mol Ther, 1998. 4(2): p. 113-20.

59. Nakajima A, Takahashi H, Inamori M, Abe Y, Kobayashi N, Kubota K, Yamanaka S. Anaplastic carcinoma of the pancreas producing granulocyte-colony stimulating factor: a case report. J Med Case Rep, 2008. 2: p. 391. 